\title{
Cell Migration and Aggregation in the Developing Telencephalon: Pulse-Labeling Chick Embryos with Bromodeoxyuridine
}

\author{
Georg F. Striedter and Brian P. Keefer \\ Department of Neurobiology and Behavior and Center for the Neurobiology of Learning and Memory, University of \\ California at Irvine, Irvine, California 92697-4550
}

\begin{abstract}
Previous studies had concluded that the avian telencephalon develops according to an outside-in schedule of neurogenesis, with relatively little migration of young neuroblasts past older cells. These previous studies had, however, been based on the "cumulative labeling" method, which is less accurate than the "pulselabeling" method typically used in mammals. In the present study, we pulse-labeled chick embryos by injecting low doses of the thymidine analog bromodeoxyuridine (BrdU) directly into the circulatory system of chick embryos at $6 \mathrm{~d}$ of incubation. The brains of these embryos were then examined for anti-BrdU-labeled cells at postinjection survival times from $30 \mathrm{~min}$ to $10 \mathrm{~d}$. Comparisons across different survival times, as well as with cases in which BrdU was injected on day 7 , suggested that our effective pulse duration is $<24 \mathrm{hr}$. This was confirmed by injecting tritiated thymidine $24 \mathrm{hr}$ after the BrdU and seeing no double-labeled
\end{abstract}

Because the telencephalon of adult birds differs dramatically from that of adult mammals, investigators have long argued about how to homologize individual telencephalic structures between these two taxa (Karten, 1969; Northcutt and Kaas, 1995; Striedter, 1997; Aboitiz, 1999). Recent comparative embryological studies have shown that the avian and mammalian telencephalons resemble each other in early development before following divergent trajectories (Striedter, 1997; Smith Fernandez et al., 1998; Striedter et al., 1998; Puelles et al., 1999, 2000). Collectively, these studies suggest that the avian Wulst is homologous to most, if not all, of the mammalian neocortex (Medina and Reiner, 2000) and that the avian neostriatum (Neo) and ventral hyperstriatum (HV) are most readily compared with the mammalian ventrolateral pallium, including the piriform cortex, basolateral amygdala, and ventral claustrum (Puelles et al., 1999).

Interestingly, however, the avian telencephalon reportedly develops according to a strict outside-in pattern of neurogenesis (Tsai et al., 1981a,b) (Fig. 1), whereas the mammalian neocortex develops in an inside-out manner (Angevine and Sidman, 1961; Berry and Rogers, 1965; Shimada and Langman, 1970; Rakic, 1974; Bayer et al., 1991). In fact, an inside-out pattern of neurogenesis has not been reported previously in any nonmammalian vertebrate (Goffinet et al., 1986). This suggests that one "key event" in the evolution of mammalian neocortex was the acquisition of the ability of young neocortical neurons to migrate past older cells and thus establish an inside-out pattern of neurogenesis (Butler, 1994). This evolutionary scenario rests on dubious evidence, however, because rather

\footnotetext{
Received May 18, 2000; revised July 31, 2000; accepted Aug. 8, 2000.

This work was supported by National Science Foundation Grant IBN-9604299. We thank Giao Nguyen and Tonya Mead for technical assistance, Pauline Yahr for lending us her rotary microtome, Eddie Ibrahim for helping us with the autoradiography, and Frank LaFerla for access to his beautiful microscope.

Correspondence should be addressed to Georg F. Striedter, University of California at Irvine, Department of Neurobiology and Behavior, 2205 Biological Sciences II, Irvine, CA 92697-4550. E-mail: gstriedt@uci.edu.

Copyright (C) 2000 Society for Neuroscience $0270-6474 / 00 / 208021-10 \$ 15.00 / 0$
}

cells. Several deviations from the previously reported pattern of telencephalic neurogenesis were also noted. Most importantly, the cells born on day 6 in the avian Wulst, the likely homolog of mammalian neocortex, end up homogeneously distributed throughout the Wulst, which suggests that many of them are migrating past older cells. Furthermore, the cells born on day 6 in the ventral hyperstriatum and dorsal neostriatum gradually (over the course of 2-3 d) aggregate into distinct multicellular clusters, which suggests that isochronic cells in these regions adhere preferentially to one another. Finally, the data reveal a proliferative subventricular zone similar to that observed in the ganglionic eminences of mammalian embryos.

Key words: outside-in; inside-out; birth dating; thymidine; forebrain; birds

different techniques were used to determine neuronal birth dates in mammals and other vertebrates.

Specifically, the birth dating data in mammals are derived from the injection of short pulses of tritiated thymidine ( ${ }^{3} \mathrm{H}$-Thy), whereas the avian data are based on a comparative analysis of results obtained after injecting large doses of ${ }^{3} \mathrm{H}$-Thy at different days of development. The latter "cumulative labeling" method is inferior to the "pulse-labeling" method, however, because it does not permit the tracking of cells over time whenever extensive cell mixing occurs. Although this limitation is serious, previous investigators did not attempt to pulse-label avian embryos because "thymidine introduced into the egg may remain available to the embryo for a considerable period of time" (LaVail and Cowan, 1971). In addition, the "pulse-chase" paradigm that is frequently used to shorten pulse duration in vitro (Primmett et al., 1989) has serious limitations when used in ovo, primarily because an egg is a relatively closed system from which the initial ${ }^{3} \mathrm{H}$-Thy or bromodeoxyuridine (BrdU) pulse cannot be removed by the experimenter (see Materials and Methods).

To overcome these limitations, we injected relatively low doses of BrdU directly into the circulatory system of embryos in ovo. BrdU was used primarily because it can be detected immunohistochemically (Miller and Nowakowski, 1988), which makes it relatively easy to visualize only the most heavily labeled cells, e.g., by varying the chromogen used to visualize the anti-BrdU. By injecting BrdU directly into the embryo's bloodstream (rather than into the egg, as previous investigators had done), we shortened the duration of the BrdU pulse, because the BrdU would likely diff use quickly out of the embryo and into other parts of the egg. The BrdU was injected on the sixth day of incubation because the cells born on this day, in the middle period of telencephalic neurogenesis (Tsai et al., 1981a,b), are most difficult to track with the cumulative labeling method. Indeed, our BrdU pulse-labeling method revealed that several regions of the avian telencephalon do not develop according to the simple outside-in schedule of neurogenesis envisioned by previous authors. This, in turn, suggests that the ability of young neurons to migrate past older cells is not a uniquely mammalian characteristic. 


\section{MATERIALS AND METHODS}

The principal methodological obstacle to cellular birth dating in birds (and other nonmammalian vertebrates) is that ${ }^{3} \mathrm{H}$-Thy or $\mathrm{BrdU}$, when injected into an egg, will not be rapidly degraded or cleared by the maternal circulatory system as it is in mammals. Instead, the label will diffuse throughout the egg and form a reservoir of primarily unmetabolized label that remains accessible to the embryo for many hours or days (Yurkewicz et al., 1981). Thus, a single application of ${ }^{3} \mathrm{H}$-Thy to a chicken egg at early stages of incubation can label newly born cells throughout the $4-5 \mathrm{~d}$ period of telencephalic neurogenesis (Tsai et al., 1981a).

To shorten this period of ${ }^{3} \mathrm{H}$-Thy availability, one might try to use a pulse-chase paradigm in which an injection of ${ }^{3} \mathrm{H}$-Thy is followed several hours later by an application of excess unlabeled thymidine (Mulrenin et al., 1999). The pulse-chase paradigm is difficult to use in eggs, however, because the initial pulse of ${ }^{3} \mathrm{H}$-Thy or BrdU cannot be washed out, as is typically done in vitro (Bannigan, 1981). Moreover, the dynamics of thymidine and BrdU diffusion and degradation in avian eggs are clearly complex, yet primarily unknown (Hyndman and Zamenhof, 1978; Yurkewicz et al., 1981). Therefore, attempts to use the pulse-chase paradigm in eggs should be accompanied by a demonstration that the "pulse" was indeed displaced or overwhelmed by the "chase." This has never been done (Mulrenin et al., 1999). Fortunately, it is possible to shorten the period of ${ }^{3} \mathrm{H}$-Thy or BrdU availability by simpler means. For example, Yurkewicz et al. (1981) were able to obtain pulse durations of $48 \mathrm{hr}$ by injecting low doses of ${ }^{3} \mathrm{H}$-Thy into the yolk sac of chick embryos at $2 \mathrm{~d}$ of incubation. We reasoned that even shorter pulse durations might be achieved if ${ }^{3} \mathrm{H}$-Thy or BrdU is injected directly into the embryo's circulatory system (see introductory remarks).

To test this hypothesis, fertile eggs of White Leghorn Chickens were obtained from Charles River Laboratories (Preston, CT) and incubated at $99.5^{\circ} \mathrm{F}$. A small window was cut into each egg at $6 \mathrm{~d}$ of incubation (Hamburger and Hamilton, 1951, their stages 28-30). Then, 14-15 $\mu \mathrm{g}$ of BrdU (dissolved at $20 \mu \mathrm{g} / \mu \mathrm{l}$ in $\mathrm{H}_{2} \mathrm{O}$ with $0.01 \%$ Fast Green; Sigma, St. Louis, MO) was injected into one of the embryo's vitelline veins through a glass micropipette (tip diameter of $5-10 \mu \mathrm{m}$ ) that was connected to a picopump (World Precision Instruments, Sarasota, FL). Given that chick embryos at $6 \mathrm{~d}$ of incubation weigh $\sim 0.54 \mathrm{gm}$ (Bannigan, 1981), this amounts to $\sim 27-29 \mu \mathrm{g} / \mathrm{gm}$. After injection, each egg was treated with 100 $\mu \mathrm{l}$ of ampicillin $(50 \mathrm{mg} / \mathrm{ml})$ and sealed with adhesive tape. The eggs were then returned to the incubator for 30-60 min $(n=7), 1 \mathrm{~d}(n=2), 2 \mathrm{~d}(n=$ $2), 3 \mathrm{~d}(n=1), 4-5 \mathrm{~d}(n=3), 6-7 \mathrm{~d}(n=3)$, and $8-12$ additional days $(n=$ 13). Three embryos were injected with $33-34 \mu \mathrm{g}$ of BrdU at $7 \mathrm{~d}$ of age $(\sim 23-24 \mu \mathrm{g} / \mathrm{gm})$ and then incubated for 8-10 more days. Please note that chick embryos typically hatch after $20-21 \mathrm{~d}$ of incubation and that only successful cases are enumerated above.

Eventually, all embryos were anesthetized on ice and/or with sodium pentobarbital and perfused transcardially with $0.1 \mathrm{M}$ PBS, followed by Methacarn fixative (60\% methanol, $30 \%$ chloroform, and $10 \%$ glacial acetic acid). After 1-3 d of post-fixation, the brains were dissected out, dehydrated through a series of alcohols and toluene, and embedded in paraffin. Transverse sections were cut at a thickness of $20 \mu \mathrm{m}$, and every sixth section was mounted on Superfrost Plus slides (Fisher Scientific Tustin, CA). For most brains, several such series were mounted, and adjacent sections were stained with either anti-BrdU or a Nissl stain $(5 \%$ Giemsa stain in water at room temperature).

For the BrdU staining, sections were deparaffinized, treated with hydrogen peroxide $(0.3 \%$ in methanol for $10 \mathrm{~min})$, hydrated, and denatured in 3 $\mathrm{M} \mathrm{HCl}$ for $20 \mathrm{~min}$ at room temperature. They were then incubated for 30 min in $10 \%$ normal goat serum, followed by $2 \mathrm{hr}$ in a $1: 50$ dilution of biotinylated anti-BrdU (in $25 \mathrm{~mm}$ Tris-buffered saline plus $0.3 \%$ goat serum; Zymed, San Francisco, CA). After this, the sections were rinsed thoroughly, incubated with streptavidin peroxidase, and reacted with a mixture of diaminobenzidine (DAB) and hydrogen peroxide $(0.03 \%)$. In some cases, the reaction sensitivity was enhanced by using a nickel- and cobalt-intensified DAB reaction. All incubations were performed in Coverwell incubation chambers (Grace Bio-Labs, Bend, OR)

Ultimately, all sections were dehydrated, coverslipped, and examined with an Olympus Optical (Tokyo, Japan) BH-2 microscope. Photographs were shot on T-Max 100 film (Eastman Kodak, Rochester, NY), scanned at high resolution, and converted to Adobe Photoshop files (Adobe Systems, San Jose, CA). These images were contrast enhanced, primarily by inverting their luminance tables. Given the small size of labeled cell nucle relative to overall telencephalic size, it was not possible to obtain satisfactory low-power photographs of labeled telencephalic cells in embryos older than $10 \mathrm{~d}$. Therefore, the distributions of labeled cells in the older embryos were charted using a commercial system that allows labeled cells to be identified at high magnification and then mapped (using stage transducers) onto a low-resolution image of the section (Translational Technologies, San Diego, CA). Only cells that were heavily (i.e., solidly) labeled and/or contained clearly labeled nucleoli were mapped in this manner. To correlate the location of labeled cells with cytoarchitectural landmarks, we compared adjacent BrdU- and Nissl-stained sections and, in some cases, examined BrdU-stained sections that were counterstained with $0.1 \%$ aqueous basic fuchsin (Takahashi et al., 1992).

To confirm that the BrdU pulses are $<24 \mathrm{hr}$ long, we used a so-called "window-labeling" method (Repka and Adler, 1992). Specifically, one embryo was injected with BrdU on day 6 (see above), followed $24 \mathrm{hr}$ later
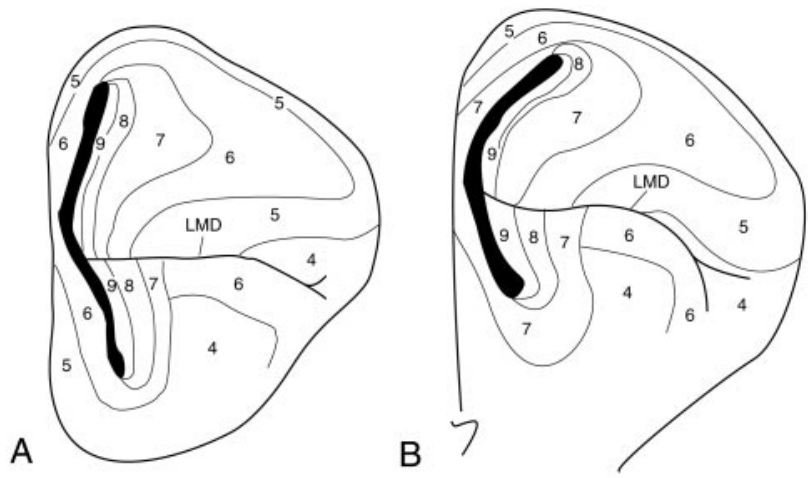

Figure 1. Isochrone map for the $10 \mathrm{~d}$ chick telencephalon as deduced by Tsai et al. (1981a,b) using the cumulative ${ }^{3} \mathrm{H}$-Thy-labeling method. The birth date designated for each isochrone zone is "the date on which $50 \%$ of the neurons first appeared unlabeled" (Tsai et al., 1981a). Therefore, these isochrone zones are highly derived abstractions, based on the statistical properties of cell populations compared across animals, and their boundaries perforce appear sharp even when cells with different birth dates intermingle extensively. Based on Tsai et al. (1981b), their Figure 8.

by an intravenous injection of ${ }^{3} \mathrm{H}$-Thy $(3 \mu \mathrm{Ci}$ per embryo, undiluted; 20 $\mathrm{Ci} / \mathrm{mmol}$; NEN, Boston, MA). The embryo was perfused on day 16 of embryogenesis and processed as described above, except that the brain was sectioned at $10 \mu \mathrm{m}$. The sections were processed for anti-BrdU staining (see above), dipped in autoradiographic emulsion (EM-1; Amersham Pharmacia Biotech, Arlington Heights, IL), exposed for 4 weeks at $4^{\circ} \mathrm{C}$, and developed according to standard procedures. The cleared sections were then examined at high magnification [with a Zeiss (Oberkochen, Germany) $100 \times$ oil immersion objective]. To determine the relative frequency of BrdU-positive, ${ }^{3} \mathrm{H}$-Thy-positive, and double-labeled cells, we counted labeled cells in 50 randomly selected optical fields in 10 different sections. If the BrdU pulse in this experiment was $<24 \mathrm{hr}$ long, then none of the cells should be double-labeled for BrdU and ${ }^{3} \mathrm{H}$-Thy (Repka and Adler, 1992).

\section{RESULTS}

We first describe the results from our short-survival experiments in which embryos are killed 30-60 min after BrdU injection on day 6 of incubation. This is followed by a description of the results obtained after injecting embryos with BrdU on day 6 and killing them at progressively longer survival times. Next, we describe the results of injecting BrdU at $7 \mathrm{~d}$ and killing the embryos a few days before hatching. Finally, we present our window-labeling data.

One difficulty encountered in describing the results of our shortand intermediate-survival experiments is that there is no universally accepted nomenclature for the early embryonic avian telencephalon. However, our BrdU data are most consistent with the nomenclature proposed by Kuhlenbeck (1938). Within the telencephalon, Kuhlenbeck recognized dorsal (D) and basal (B) divisions, which correspond to the pallium and subpallium, respectively, of other authors (Striedter, 1997). Within these major divisions, Kuhlenbeck recognized seven longitudinal cell columns, named D1-D3 and B1-B4. This nomenclature had not been widely adopted, however, primarily because the boundaries between many of Kuhlenbeck's longitudinal columns are difficult to see in Nisslstained sections. It is important, therefore, to note that we use Kuhlenbeck's terminology only to the extent that it is supported by our BrdU data. A full discussion of how the BrdU data relate to the early embryonic compartmentalization of the avian telencephalon is, however, beyond the scope of the present paper (Striedter and Beydler, 1997; Puelles et al., 1999, 2000). In describing the results of our long-survival experiments, we use the nomenclature most commonly used to describe newly hatched and adult chicken brains (van Tienhoven and Juhász, 1962; Youngren and Phillips, 1978; Kuenzel and Masson, 1988).

In general, the BrdU labeling obtained with the nickelintensified DAB-black reaction was more intense and more numerous than the labeling generated by the regular DAB-brown reaction. Therefore, the overall pattern of BrdU labeling is most easily seen in low-power photomicrographs of DAB-black-stained sec- 

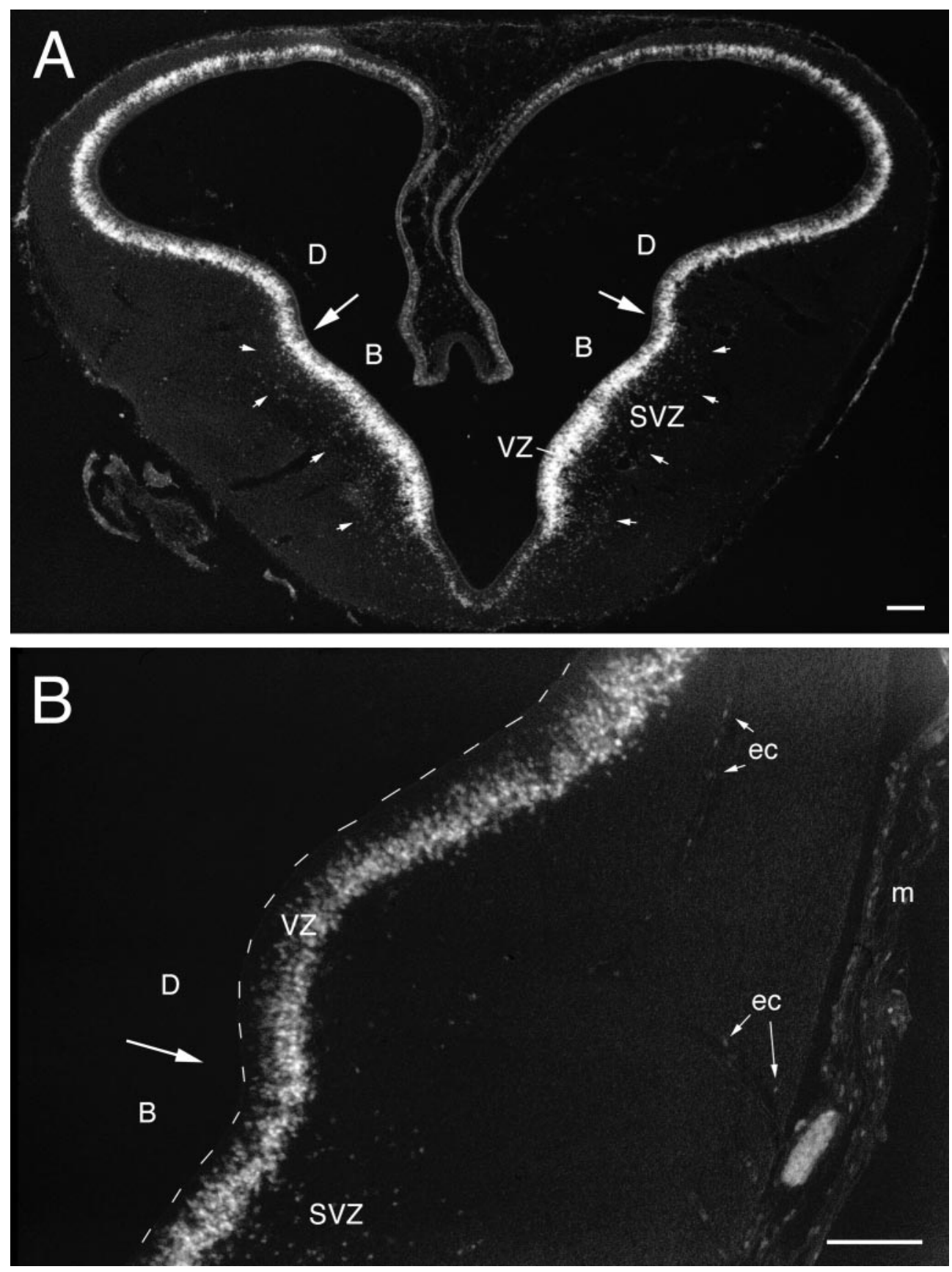

Figure 2. Photomicrograph (negative image) of a transverse section through the telencephalon of a 6-d-old chick embryo (Hamburger and Hamilton, 1951, their stage 28-29) that was injected with BrdU 30 min before being killed. $A$ illustrates a section that was stained with anti-BrdU and DAB-black. Anti-BrdU-labeled nuclei are found throughout the $\mathrm{VZ}$ and, less densely, in an SVZ, which is outlined by the small white arrows. The large arrows point to the pallial-subpallial boundary, which is evident as a slight but consistent change in the pattern of BrdU labeling within the VZ and approximately coincident with the dorsal boundary of the SVZ. $B$ is taken from a similar section reacted with DAB-brown. Here, it can be seen that the heavily labeled nuclei are found predominantly in the superficial portion of the VZ. Labeled nuclei are also found in the meninges $(\mathrm{m})$ and in some of the endothelial cells $(e c)$ that line blood vessels. Scale bars, $100 \mu \mathrm{m}$. tions (Fig. $2 A$ ). On the other hand, the distinction between weakly and heavily labeled cells is more readily seen in DAB-brownstained sections (Fig. 2B). Consequently, the following description is based primarily on the results obtained with the DAB-brown reaction, except in some cases in which this technique by itself was not sensitive enough to reveal a significant number of labeled nuclei.

\section{Short survival after BrdU injections on day 6}

Thirty minutes after BrdU injection on day 6, labeled nuclei are found throughout the telencephalic ventricular zone (VZ). The most heavily labeled nuclei are located in the superficial portion of the VZ, weakly labeled nuclei predominate in the intermediate portion of the VZ, and virtually no labeled nuclei are adjacent to the ventricular surface. This distribution is consistent with the idea that the nuclei of VZ cells are located superficially during $\mathrm{S}$ phase and then translocate toward the ventricular surface where they eventually divide (Sidman et al., 1959; Alvarez-Buylla et al., 1998).
The weakly labeled nuclei in the intermediate VZ probably finished $\mathrm{S}$ phase and began moving toward the ventricle early on during the BrdU pulse.

The pattern of BrdU labeling clearly differs between the basal and dorsal divisions of the embryonic telencephalon. Most prominently, a 100- to 200- $\mu \mathrm{m}$-thick band of labeled cells is found superficial to the $\mathrm{VZ}$ in the dorsolateral portion of the basal telencephalon (Kuhlenbeck, 1938, his B1 and B2) but not in the dorsal telencephalon or in other parts of the basal telencephalon (Fig. 2A). We refer to this band of labeled non-VZ cells in the dorsolateral basal telencephalon as the subventricular zone (SVZ) because (1) it is located in approximately the same location as the mammalian SVZ (Smart, 1985), (2) its cells are not associated with blood vessels (i.e., they are not endothelial cells; see below), and (3) a survival time of $30 \mathrm{~min}$ is not long enough for cells to synthesize new DNA, divide, and migrate out of the VZ. Therefore, the cells in the avian SVZ are most likely synthesizing new DNA and dividing outside of the VZ, which is a cardinal feature of the SVZ 

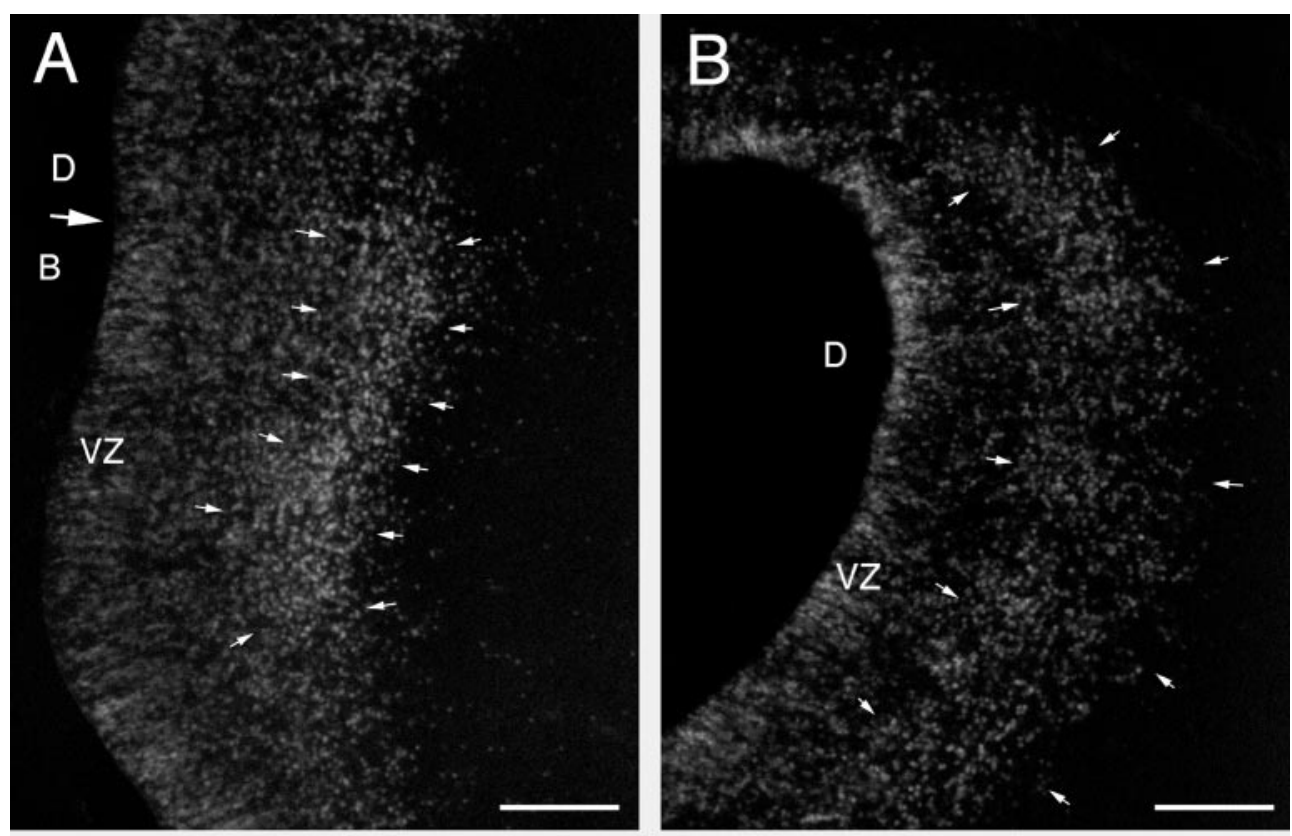

Figure 3. Labeled cells in the telencephalon of embryos that were injected with $\mathrm{BrdU}$ at $6 \mathrm{~d}$ and killed at 7 and $8 \mathrm{~d}$ of incubation. At $7 \mathrm{~d}(A, B)$, most of the heavily labeled cells form a band (outlined by small arrows) that parallels the VZ and is separated from the latter by a zone of less heavily labeled cells. This band is most evident in the dorsolateral portion of the basal telencephalon $(A)$, but it can be seen also in the lateral portion of the dorsal telencephalon $(B)$. The labeling at $8 \mathrm{~d}(C, D)$ is similar to that observed on day 7 , except that the band of labeled cells has widened, particularly in the dorsolateral telencephalon $(D 1)$. Note that the band of heavily labeled nuclei does not, at these ages, reach the brain surface or contain any prominent clusters (compare with Fig. 4). The small asterisks indicate the tongue-like extension of labeled cells just ventral to the LMD (see Results). The large arrows point to the medial and lateral limits of the pallial-subpallial $(D-B)$ boundary, as determined from adjacent Nissl-stained sections. The boundary between B1 and B2 of Kuhlenbeck (1938) is difficult to see in these sections but is apparent in other sections as a difference in the BrdU-labeling pattern. Scale bars, $100 \mu \mathrm{m}$.
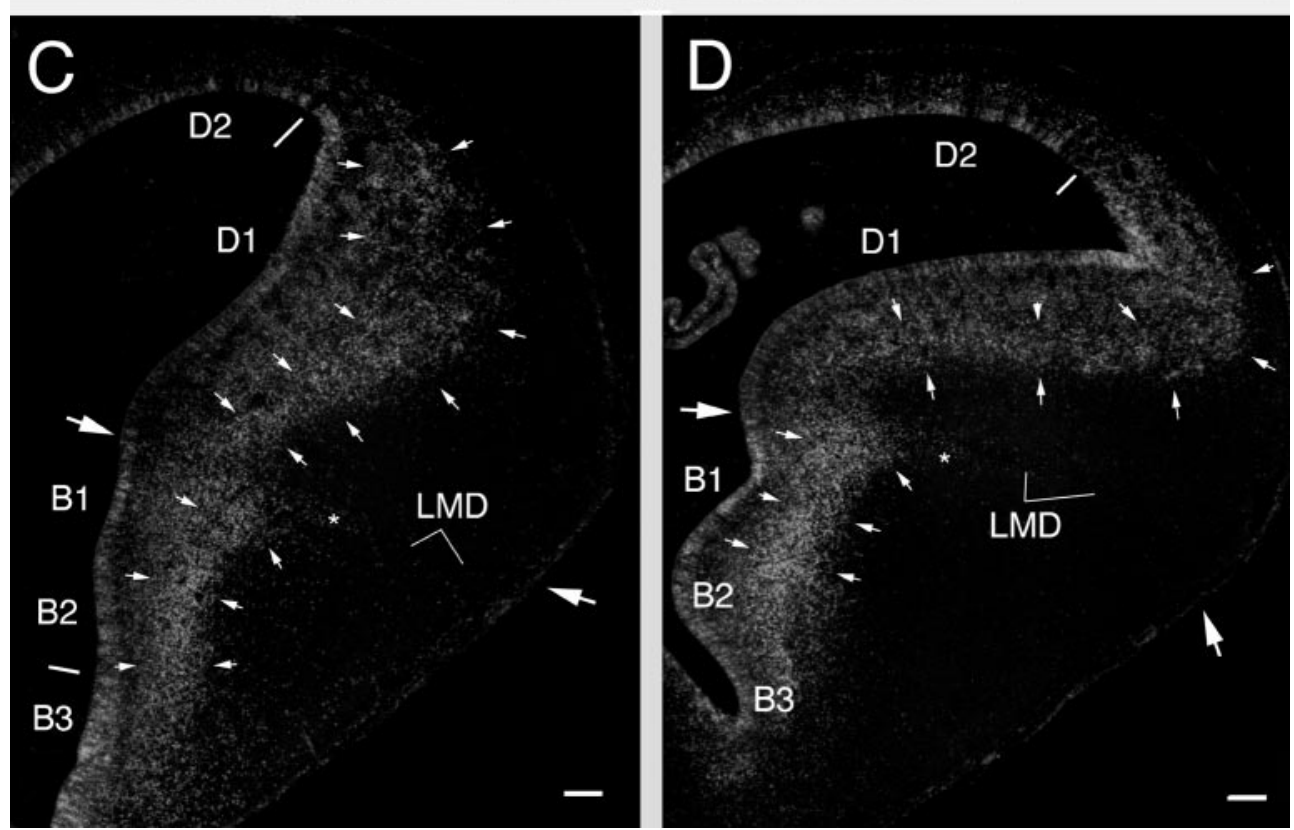

also in mammals (Boulder-Committee, 1970; Sidman and Rakic, 1982).

In addition, many BrdU-labeled nuclei are found in the meninges and adjacent to intratelencephalic blood vessels (Fig. 2B). The latter are likely to be the nuclei of endothelial cells. Very little BrdU labeling is seen in the thin ependymal zone of the dorsomedial telencephalon.

\section{Intermediate survival after BrdU injections on day $\mathbf{6}$}

On day 7, i.e., $1 \mathrm{~d}$ after BrdU injection, the basal and dorsal regions of the telencephalon again exhibit different labeling patterns (Fig. $3 A, B)$. In the basal telencephalon, the most heavily labeled cells are concentrated in a region $\sim 100 \mu \mathrm{m}$ superficial to the ventricle and form a band or ribbon in transverse sections (Fig. $3 A$, between the small arrows). In the lateral portion of the dorsal telencephalon, heavily labeled cells are also concentrated in a band at some distance from the ventricle (Fig. $3 B$ ), but the density of labeled cells in this dorsal band is lower than it is in the basal band. Conversely, the density of heavily labeled nuclei in the VZ is higher in the dorsolateral telencephalon than it is in the basal telencephalon (Fig. $3 A, B$ ). Very few labeled cells are seen in the most dorsome-

dial telencephalon, and only faintly labeled nuclei are found along the intratelencephalic blood vessels and in the meninges.

By the eighth day of incubation, heavily labeled nuclei in the VZ have become relatively rare but can still be found, particularly in the dorsolateral portion of the basal telencephalon and around the ventricular angle in the dorsal telencephalon (Fig. 3C,D). Outside of the VZ, the highest density of heavily labeled cells is found (as on day 7) in a band of label than runs parallel to the VZ in the dorsolateral portion of the basal telencephalon (Kuhlenbeck, 1938, his B1 and B2) (Fig. 3C,D). A tongue-like, laterally directed extension of labeled cells can be seen just ventral to the pallialsubpallial boundary, which at this age corresponds to the lamina medullaris dorsalis (LMD) (Fig. 3C,D). In the ventrolateral portion of the basal telencephalon (Kuhlenbeck, 1938, his B3) heavily labeled cells are scattered rather homogeneously throughout the depth of the brain. In the lateral portion of the dorsal telencephalon (Kuhlenbeck, 1938, his D1), the band of heavily labeled cells that was already evident on day 7 is now thicker than it was on the day before and spans up to $450 \mu \mathrm{m}$ in the radial direction. The distribution of labeled cells within this band is less homogeneous 

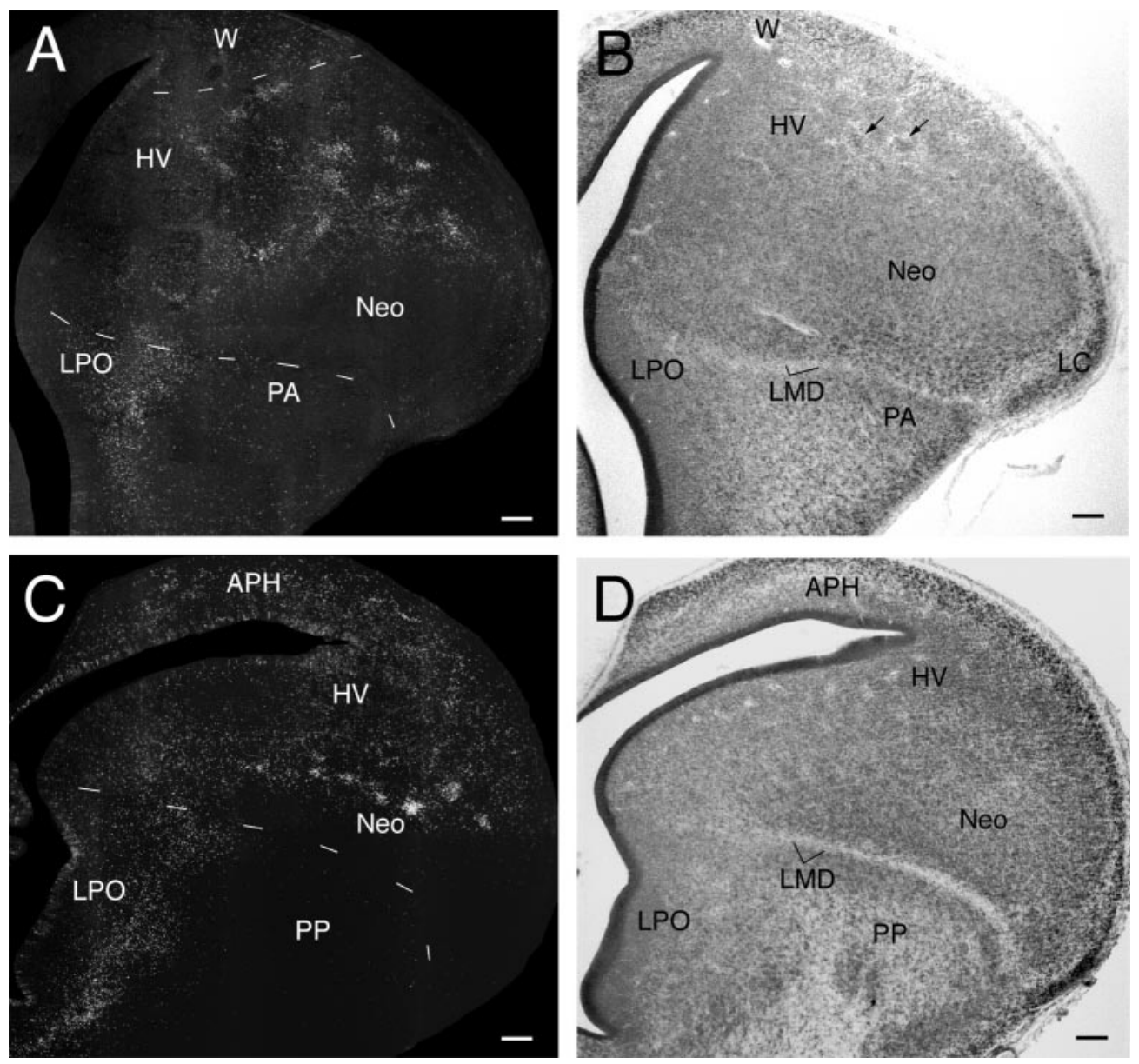

Figure 4. Transverse sections through the brain of a 9-d-old embryo that was injected with BrdU on day 6. $A$ and $B$ represent adjacent sections at a midtelencephalic level, stained with anti-BrdU and a Nissl stain, respectively. $C$ and $D$ represent similarly stained sections at a cauda telencephalic level. The pallial-subpallial boundary is clearly demarcated at this age by the LMD, but $\mathrm{HV}$ and Neo are not yet separated by a definite boundary. A faint boundary courses between $\mathrm{HV}$ and the Wulst $(W)$, which is not yet divisible into HA and HD at this age. The pattern of anti-BrdU labeling clearly differs between the Wulst, the HV-Neo complex, and the paleostriatum $[L P O, P A$, and primitive paleostriatum $(P P)]$. Most obviously, the labeled nuclei in the dorsal portion of the $\mathrm{HV}-\mathrm{Neo}$ complex form clusters that were not evident at $8 \mathrm{~d}$. Examination of the Nissl-stained sections shows that the unlabeled regions between the clusters are not devoid of cells. Some cells in the dorsal HV-Neo complex do, however, seem to form clusters even in Nissl-stained sections (see arrows in $B$ ). $A P H$, Parahippocampal area. Scale bars, $100 \mu \mathrm{m}$. than it was on day 7 , with small cluster-like condensations of labeled cells being apparent in several locations. In the dorsal portion of the dorsal telencephalon (Kuhlenbeck, 1938, his D2), heavily labeled cells are found primarily in a 50- to $100-\mu \mathrm{m}$-thick band adjacent to the VZ. Labeled endothelial and meningeal cells are weakly labeled at this age and apparent only in DAB-black material.

\section{Long survival after BrdU injections on day 6}

By $9 \mathrm{~d}$, the VZ is mostly devoid of labeled cells, except in its most dorsal and caudal portions (Fig. 4). The band of labeled cells in the basal telencephalon is now more dispersed mediolaterally but remains fundamentally similar to what it looked like on day 8 . The dorsal telencephalon can be tentatively divided into Neo and HV, but a definite boundary between these two regions has yet to form (Striedter and Beydler, 1997). Interestingly, labeled cells in the dorsal portion of the HV-Neo complex form clusters of 30-100 cells (as seen in 20- $\mu$ m-thick sections) (Fig. $4 A, C$ ). Some of these clusters coincide, at least approximately, with heterogeneities seen in the adjacent Nissl-stained sections (Fig. 4B), but this was not the case for all clusters. Cluster formation in the ventral portion of the HV-Neo complex is less pronounced than it is in the dorsal portion. Labeled cells in the avian Wulst, which is derived from Kuhlenbeck's (1938) D2 region (Fig. 3C,D), are dispersed rather homogeneously from the VZ to the brain surface without any evidence of cluster formation. In the parahippocampal area and hippocampal formation, heavily labeled cells are concentrated in the VZ and at intermediate depths, but they occasionally occur also near the brain surface.

At $10 \mathrm{~d}$ of age, the Wulst can be divided into dorsal hyperstriatum (HD) and accessory hyperstriatum (HA) (we include the intercalated hyperstriatum within HD), and HV is clearly demarcated from Neo. Yet the pattern of BrdU labeling is similar to what it was a day earlier. Clusters of labeled cells occur throughout large parts of $\mathrm{HV}$, particularly at intermediate depths, and these clusters are similar in size to those seen on the day before (Fig. 5). Without three-dimensional reconstructions, however, cluster size (in terms of number of cells within a cluster) cannot easily be compared across ages, because cell density in the avian telencephalon generally decreases with age. Some clusters of heavily labeled cells are also evident in the neostriatum, particularly along its dorsal rim (Fig. 5B). The ventrolateral neostriatum (including ectostriatum and nucleus basalis) is markedly devoid of heavily labeled cells (Fig. 5A,B). Some heavily labeled cells are located near the dorsolateral brain surface, including the lateral corticoid area (LC). In the basal telencephalon, heavily labeled cells are concentrated in a band along the lateral edge of the lobus parolfactorius (LPO), probably including the medial parts of the augmentated paleostriatum (PA). The tongue-like extension of labeled cells just ventral to LMD (Fig. 3, compare $C, D$ ) is now quite elongated and constitutes part of PA (Fig. $5 A$ ).

By 14-18 d of incubation, the chick telencephalon has expanded in size, primarily because of a significant decrease in cell density, and looks remarkably similar to the telencephalon of an adult chicken. The pattern of BrdU labeling is generally similar to that seen at day 10, except that the density of labeled cells (per unit area) has decreased and somewhat fewer clusters are apparent in any given $20 \mu \mathrm{m}$ section (Fig. 6). Field $\mathrm{L}$ is now apparent as a dense region of smaller cells in the caudal neostriatum, but it is relatively devoid of labeled cells. Numerous labeled cells (but few obvious clusters) are found in the most caudal and dorsolateral regions of the telencephalon in which the ventricle and its associated VZ have largely disappeared (Fig. 6C).

\section{Long survival after BrdU injection on day 7}

When BrdU was injected at $7 \mathrm{~d}$, the pattern of labeled cells observed at 14-18 d (Fig. 7) differs dramatically from that observed when the BrdU injections were made on day 6 . In general, the areas 

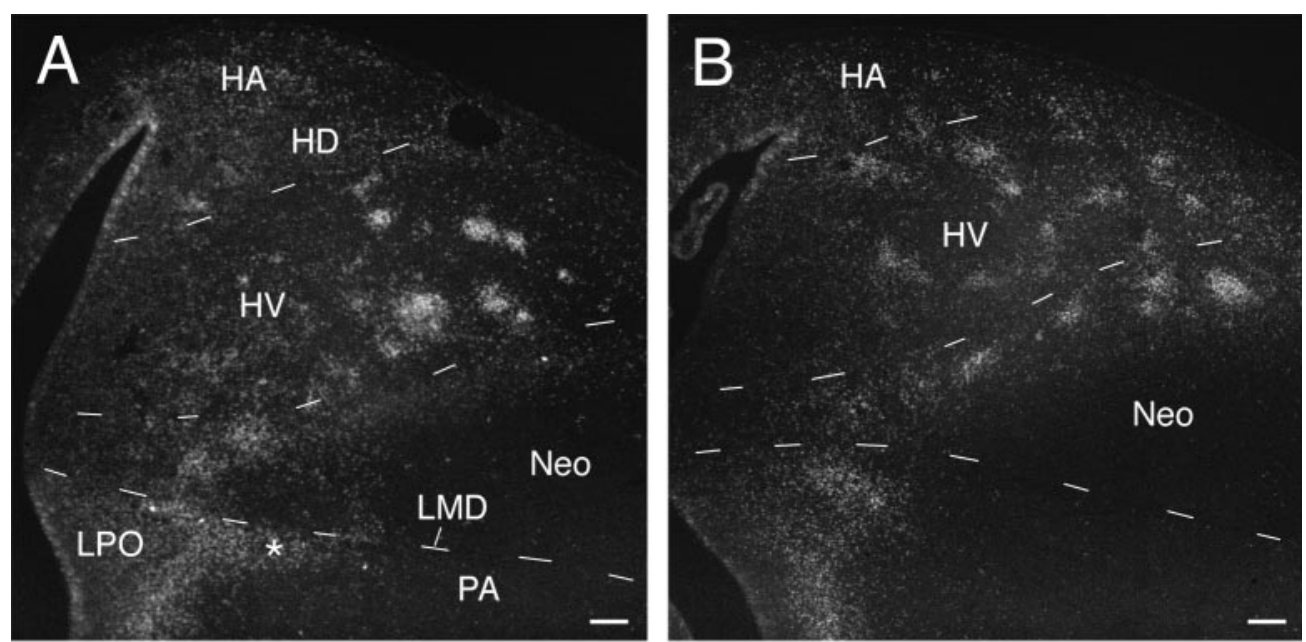

Figure 5. Transverse sections through the brain of a 10-d-old embryo injected with BrdU on day 6 . The section in $A$ is rostral to that in $B$. $C$ and $D$ are higher magnification views of areas in $A$ and $B$, respectively. At this age, $\mathrm{HV}$ and $\mathrm{Neo}$ are clearly demarcated from one another, making it possible to state unequivocally that clusters of anti-BrdU-labeled cells occur in both HV and parts of Neo (particularly along its dorsal edge). Labeled cells in HA and $\mathrm{HD}(C)$ do not cluster as they do in $\mathrm{HV}(D)$ and are distributed rather homogeneously from the VZ to the brain surface. The asterisk in $A$ denotes the tongue-like extension of labeled cells just ventral to LMD. Scale bars, $100 \mu \mathrm{m}$.
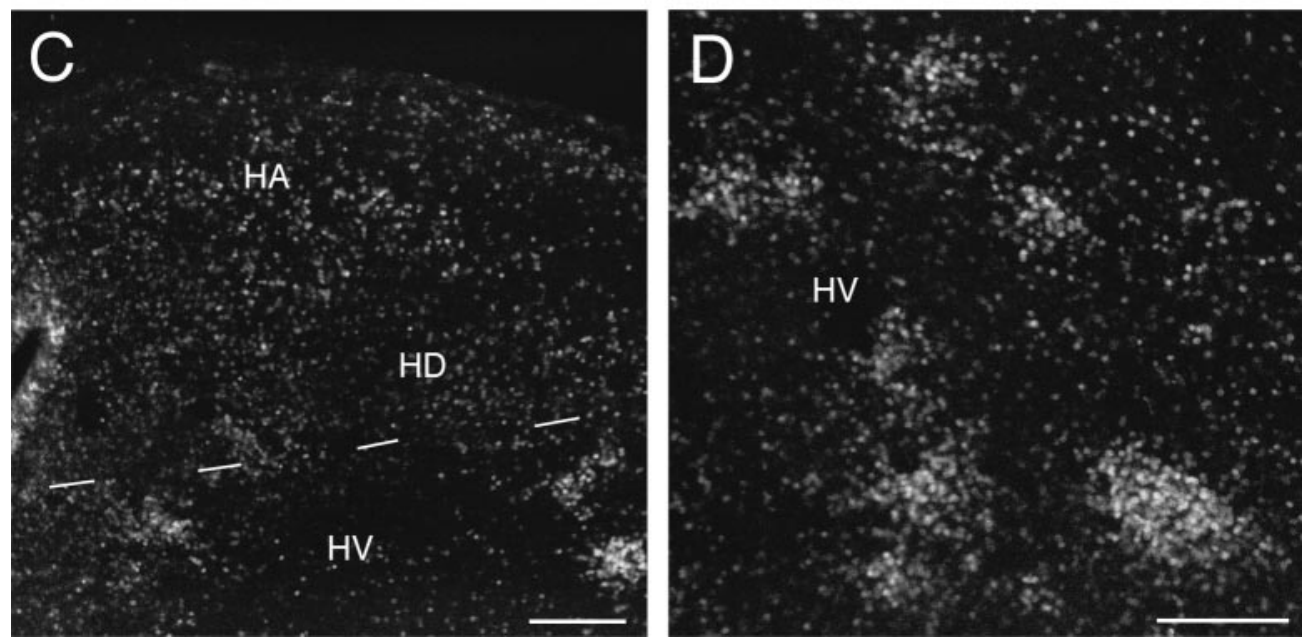

with high concentrations of labeled cells are located closer to the $\mathrm{VZ}$ than they are in the $6 \mathrm{~d}$ cases. Specifically, numerous labeled cells are seen in the deepest portions of LPO, PA, Neo, and hippocampal formation. Some clusters of labeled cells are observed in $\mathrm{HV}$, but these are located more medially than the analogous clusters in the $6 \mathrm{~d}$ cases. Labeled cells are found throughout the depth of Wulst (particularly HA), but the distribution of these cells is not as homogeneous as it is in the $6 \mathrm{~d}$ cases. Numerous labeled cells are located in LC and in the most superficial region of $\mathrm{HV}$ and Neo.

\section{Window labeling with BrdU and ${ }^{3} \mathrm{H}$-Thy}

When BrdU was injected on day 6 and followed by an injection of ${ }^{3} \mathrm{H}$-Thy on day 7 , both BrdU- and ${ }^{3} \mathrm{H}$-Thy-positive cells were observed, but virtually no cells were positive for both BrdU and ${ }^{3}$ H-Thy (Fig. 8). Our cell count revealed 2161 BrdU-positive cells (including weakly labeled cells), $527{ }^{3} \mathrm{H}$-Thy-positive cells (defined as clusters of 12 or more silver grains in an area the size of a typical cell nucleus), and only 14 cells that seemed to be double-labeled. The observed double-labeling is probably an artifact attributable to the chance superposition of BrdU- and ${ }^{3} \mathrm{H}$-Thy-positive cells within a section. This hypothesis is supported by the observation that the weakly BrdU-positive cells, which are likely to have been born toward the end of the BrdU pulse, were no more likely to appear double-labeled than the strongly BrdU-positive cells (Fig. $8)$. Therefore, we conclude that our BrdU pulse is likely to have been $<24 \mathrm{hr}$ long. In addition, we note that the observed pattern of ${ }^{3} \mathrm{H}$-Thy labeling is similar to that obtained after injecting BrdU on day 7 (see above) and different from that seen when $20 \mu \mathrm{Ci}$ of ${ }^{3} \mathrm{H}$-Thy are dripped into an egg (Tsai et al., 1981a,b; our unpublished observations). These findings suggest that the ${ }^{3} \mathrm{H}$-Thypositive cells in our case were born exclusively on day 7 . Therefore, our intravenous injection technique can apparently be used to pulse label embryos with ${ }^{3} \mathrm{H}$-Thy, as well as BrdU.

\section{DISCUSSION}

The method described in the present study effectively labels cells that are born during a limited period of embryonic development, but some methodological concerns remain and are discussed below. This is followed by a description of the cellular dynamics that underlie telencephalic development in chicks. The final section of this paper deals with the comparative and evolutionary aspects of telencephalic development.

\section{Methodological concerns}

Given our methods and considering only the heavily labeled cells, we are confident that our BrdU pulse is $<1 \mathrm{~d}$ long, because $24 \mathrm{hr}$ after BrdU administration, (1) heavy BrdU labeling is scarce in several regions of the telencephalic VZ, (2) the band of heavily labeled nuclei in the dorsolateral portion of the basal telencephalon is separated from the VZ by less heavily labeled cells, and (3) the continuously proliferating endothelial and meningeal cells are but weakly stained. In addition, BrdU administration at $7 \mathrm{~d}$ yields results that are clearly different from those obtained when BrdU is injected on day 6. Finally, injection of ${ }^{3} \mathrm{H}$-Thy $24 \mathrm{hr}$ after a BrdU pulse on day 6 yields essentially no double-labeled cells, which indicates that the BrdU pulse must have ended before the ${ }^{3} \mathrm{H}$-Thy was injected. Indeed, we suspect that our BrdU pulses are significantly shorter than $24 \mathrm{hr}$ (Takahashi et al., 1992), because the cells in the intercluster regions of $\mathrm{HV}$ do not appear to be born on either day 7 or 5 (Fig. 7) (our unpublished observations). They are therefore likely to be born during day 6 but before and/or after the BrdU pulse.

Most of the heavily labeled cells at intermediate and long sur- 


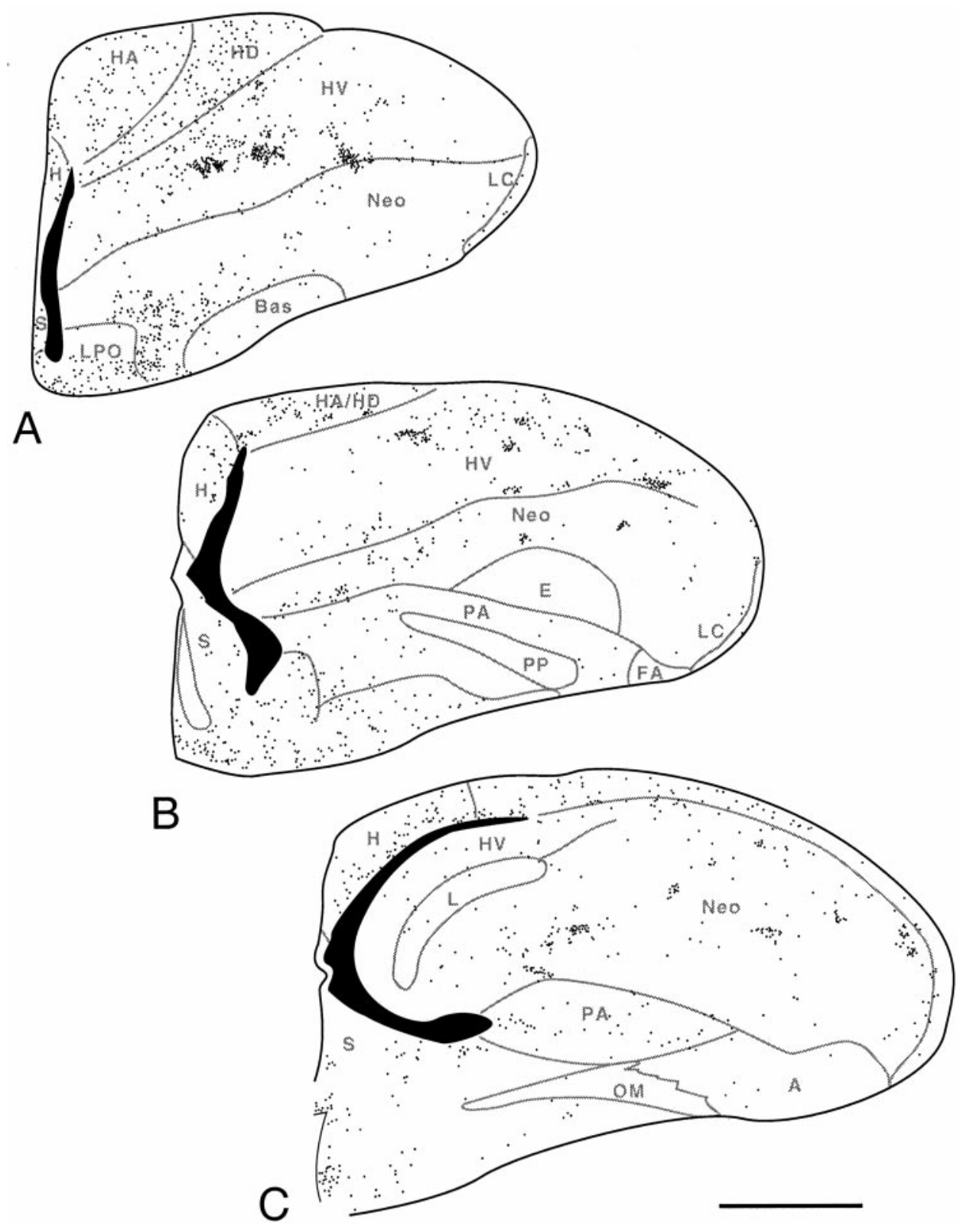

Figure 6. Charting of anti-BrdU-labeled cells in transverse sections through the telencephalon of a 16-d-old embryo injected with BrdU on day 6 . The boundaries between major brain regions were inferred from adjacent Nisslstained sections but confirmed (as much as possible) by examining the anti-BrdU-labeled section with dark-field illumination. The sections are arranged from rostral to caudal ( $A$ to $C)$. Scale bar, $100 \mu \mathrm{m}$. $A$, Archistriatum; Bas, nucleus basalis; $E$, ectostriatum; $F A$, frontoarchistriatal tract; $H$, hippocampal formation; $L$, field L; $O M$, occipitomesencephalic tract; $P P$, primitive paleostriatum; $S$, septum. vival times are likely to be neurons because (1) heavy BrdU labeling is observed along blood vessels and in the meninges only with short survival times, and (2) most of the labeled nuclei outside of the VZ at longer survival times are relatively large, round, or oval, and generally resemble the nuclei that are labeled by a neuron-specific antigen (our unpublished observations using antiNeuN) (Mullen et al., 1992). Tsai et al. (1981a) similarly concluded from their autoradiographic data that most of the cells born on days 6-7 are neurons and that most of the glia are born after day 10 of embryogenesis (Goffinet et al., 1986). This is consistent with our unpublished observation that the small and irregularly shaped nuclei typically found in glia are more frequently labeled when BrdU is injected after $8 \mathrm{~d}$ of incubation.

\section{Histogenesis in the chick telencephalon}

The work of Tsai et al. (1981a,b) with the cumulative labeling method suggested that the avian telencephalon develops according to an outside-in schedule of neurogenesis, with young neurons always accumulating deep to older ones and relatively little migration of young neurons past older ones (Fig. 1). Tsai et al. noted that there might be some deviations from this pattern, but they did not report on these in detail, and subsequent investigators rarely mentioned any exceptions. Thus, even the avian Wulst, the most likely homolog of mammalian neocortex, is said to develop according to an outside-in schedule of neurogenesis (Reiner and Karten, 1983). Our data contradict this simple view and show that the conclusions of Tsai et al. were correct only for some telencephalic regions and only with respect to "average" neuronal birth dates. Three specific discrepancies deserve special mention.

First, the avian Wulst cannot be generated according to an outside-in schedule of neurogenesis because the cells born on day 6 end up scattered throughout the depth of both HA and HD, the two major Wulst components in chicks. Because neurons in the Wulst are born over a relatively long period of time (from day 4 to day 9 of incubation) (Tsai et al., 1981a), this scattered distribution of day 6 cells implies that a considerable number of cells in the Wulst migrate past older cells. Similar migrations past older cells are likely to occur in the Wulst also on days 7 and 8 of embryonic development, as the cells born on these days are similarly scattered throughout the depth of the Wulst (Fig. 7) (our unpublished observations). Most of the migration in the Wulst probably occurs along radial glial fibers (Striedter and Beydler, 1997; Medina and Reiner, 2000), but it is possible that some older cells migrate into the Wulst along nonradial trajectories (Anderson et al., 1997).

Second, a strict outside-in pattern of development is inconsistent 
Figure 7. Charting of anti-BrdU-labeled nuclei in transverse sections through the telencephalon of a 16-d-old embryo injected with BrdU on day 7. Conventions are as for Figure 6.

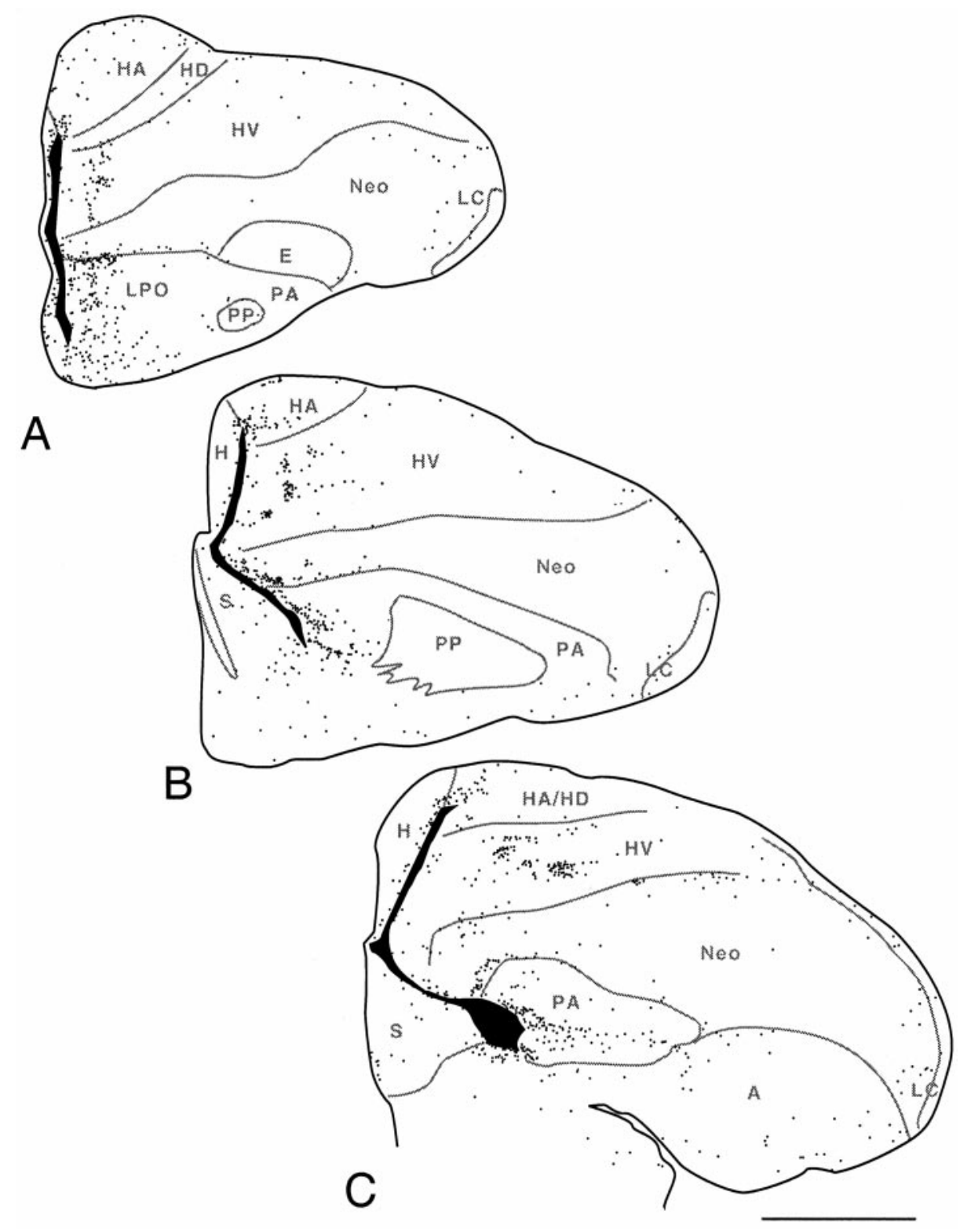

preferential adhesion between isochronic cells. Alternatively, the clusters might form from relatively late bursts of proliferation by cells outside the VZ, but this seems unlikely given our failure to see similar clusters when BrdU is injected at 9 or $10 \mathrm{~d}$ of incubation (our unpublished observations). Similarly, it seems unlikely that the clusters form because of selective cell death in the intercluster regions because the Nissl stains reveal the intercluster regions to be full of cells. It is possible, however, that a modicum of selective cell death (e.g., of cells that are isolated from other cells with similar times of birth) contributes to cluster formation. Additional aspects of these clusters that will have to await further clarification are their three-dimensional structure, consistency across animals, and adult fate.

\section{Telencephalic evolution}

Historically, much of the literature on forebrain evolution emphasized comparisons between adult brains and yielded little consensus, particularly in comparisons between avian and mammalian telencephalons (Striedter, 1997). Considerable progress has been made recently, however, by comparing embryonic rather than adult telencephalons and using immunohistochemical and gene expression data (Striedter and Beydler, 1997; Smith Fernandez et al., 1998; Puelles et al., 1999, 2000; Medina and Reiner, 2000). Funda- $\mathrm{d}$ after their cells are born, from an apparently homogeneous distribution of labeled cells, they are likely to be the result of
Finally, there had been no previous report of any clustering among avian telencephalic cells with similar birth dates. Because the clusters we observed here are widely scattered throughout HV and the dorsal neostriatum and are separated by regions of cells with different birth dates, they are inconsistent with any simple outside-in pattern of neurogenesis. Given that the clusters form 2-3 


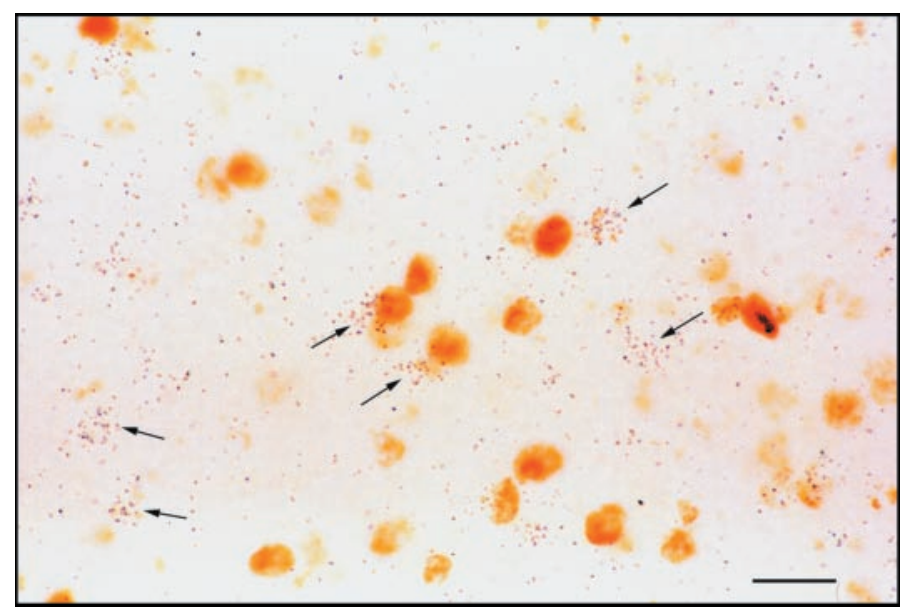

Figure 8. High-power photomicrograph of the window-labeling data. Cells are positive for either BrdU (brown reaction product) or ${ }^{3} \mathrm{H}$-Thy (arrows) but not for both. Scale bar, $10 \mu \mathrm{m}$.

mental to these efforts has been the notion that the embryonic brain is divisible into a hierarchically organized set of developmental "compartments" (Bergquist and Källén, 1953; Garcia-Bellido et al., 1979), which can be homologized even if some of the adult structures derived from them are difficult or impossible to homologize in a simple one-for-one manner (Striedter, 1999).

In this context, the data presented here are important because they provide evidence for several compartmental boundaries. Specifically, the short-survival data support the division of the embryonic telencephalon into a pallium and several subpallial cell columns (Kuhlenbeck, 1938; Källén, 1962). In the long-survival experiments, the tongue-like protrusion of day 6 cells just ventral to the LMD (Figs. 3-5) supports the hypothesis that the LMD is a lineage restriction boundary that separates pallium from subpallium (Striedter et al., 1998). The finding that day 6 cells are distributed homogeneously throughout the Wulst, but clustered in $\mathrm{HV}$, supports the hypothesis that these two structures form separate developmental compartments with distinct modes of cell migration and aggregation. The data do not provide strong support for the hypothesis that $\mathrm{HV}$ and $\mathrm{Neo}$ are separate developmental compartments because very similar isochronic cell clusters are found in $\mathrm{HV}$ and the dorsal neostriatum (Striedter and Beydler, 1997). However, this conclusion can be reconciled with the comparative gene expression data, which suggest that $\mathrm{HV}$ and Neo are separate compartments (Puelles et al., 1999, 2000), if HV and Neo become partially interdigitated during development (e.g., by the migration of some HV cells into the dorsal Neo; L. Puelles, personal communication). More research is clearly needed, however, to resolve this issue.

In addition to homologizing brain regions or compartments, one may also examine the evolution of developmental mechanisms. From this perspective, the present data are important because they show that migration past older cells is not unique to mammalian neocortex. To determine whether the ability to migrate past older cells evolved twice independently in birds and mammals or just once, in a common ancestors of reptiles, birds, and mammals, it will be necessary to perform more detailed analyses of neurogenesis in amphibians and reptiles (Goffinet et al., 1986). Similarly, the present data show that a subpallial SVZ is not unique to mammals but, again, they leave open the question as to whether the SVZ evolved twice independently in birds and mammals or just once in a common ancestor of these two taxa. In either case, the SVZ probably evolved as an adaptation for rapid cellular proliferation (Smart and Sturrock, 1979). Finally, it is interesting to note that isochronic cell clusters are found in both the avian $\mathrm{HV}-\mathrm{Neo}$ complex and the mammalian striatum (Brand and Rakic, 1979; van der Kooy and Fishell, 1987). Because the avian HV-Neo complex is clearly not homologous to the mammalian striatum (Juorio and
Vogt, 1967; Karten, 1969; Reiner et al., 1984), the clusters in the $\mathrm{HV}-\mathrm{Neo}$ complex probably evolved independently of those in the mammalian striatum. Nonetheless, the isochronic cell clusters in both birds and mammals may well form as a result of similar, phylogenetically conserved, molecular and cell biological mechanisms (Korematsu et al., 1998; Janis et al., 1999).

\section{REFERENCES}

Aboitiz F (1999) Comparative development of the mammalian isocortex and the reptilian dorsal ventricular ridge: evolutionary considerations. Cereb Cortex 9:783-791.

Alvarez-Buylla A, García-Verdugo JM, Mateo AS, Merchant-Larios H (1998) Primary neural precursors and intermitotic nuclear migration in the ventricular zone of adult canaries. J Neurosci 18:1020-1037.

Anderson SA, Eisenstat DD, Shi L, Rubenstein JLR (1997) Interneuron migration from basal forebrain to neocortex: dependence on Dlx genes. Science 278:474-476.

Angevine JB, Sidman RL (1961) Autoradiographic study of cell migrations during histogenesis of cerebral cortex in mouse. Nature 192:766-768.

Bannigan J (1981) The uptake of 5-bromodeoxyuridine by the chicken embryo and its effects upon growth. Anat Embryol (Berl) 162:425-434.

Bayer SA, Altman J, Russo RJ, Dai X, Simmons JA (1991) Cell migration in the rat embryonic neocortex. J Comp Neurol 307:499-516.

Bergquist H, Källén B (1953) On the development of neuromeres to migration areas in the vertebrate cerebral tube. Acta Anat (Basel) 18:65-73.

Berry M, Rogers AW (1965) The migration of neuroblasts in the developing cerebral cortex. J Anat 99:691-709.

Boulder Committee (1970) Embryonic vertebrate central nervous system: revised terminology. Anat Rec 166:257-262.

Brand S, Rakic P (1979) Genesis of the primate neostriatum: $\left[{ }^{3} \mathrm{H}\right]$ thymidine autoradiographic analysis of the time of neuron origin in the rhesus monkey. Neuroscience 4:767-778.

Butler AB (1994) The evolution of the dorsal pallium in the telencephalon of amniotes: cladistic analysis and a new hypothesis. Brain Res Rev 19:66-101.

Garcia-Bellido A, Lawrence PA, Morata G (1979) Compartments in animal development. Sci Am 241:102-110.

Goffinet AM, Daumerie CH, Langerwerf B, Pieau C (1986) Neurogenesis in reptilian cortical structures: ${ }^{3} \mathrm{H}$-thymidine autoradiographic analysis. J Comp Neurol 243:106-116.

Hamburger V, Hamilton HL (1951) A series of normal stages in the development of the chick embryo. J Morphol 88:49-92.

Hyndman AG, Zamenhof S (1978) Thymidine phosphorylase, thymidine kinase and thymidylate synthetase activities in cerebral hemispheres of developing chick embryos. J Neurochem 31:577-580.

Janis LS, Cassidy RM, Kromer LF (1999) Ephrin-A binding and EphA receptor expression delineate the matrix compartment of the striatum. J Neurosci 19:4962-4971.

Juorio AV, Vogt M (1967) Monoamines and their metabolites in the avian brain. J Physiol (Lond) 189:489-518.

Källén B (1962) Embryogenesis of brain nuclei in the chick telencephalon. Erg Anat Entwicklungsgesch 36:62-82.

Karten HJ (1969) The organization of the avian telencephalon and some speculations on the phylogeny of the amniote telencephalon. Ann NY Acad Sci 167:164-179.

Korematsu K, Goto S, Okamura A, Ushio Y (1998) Heterogeneity of cadherin-8 expression in the neonatal rat striatum: comparison with striatal compartments. Exp Neurol 154:531-536.

Kuenzel WJ, Masson M (1988) A stereotaxic atlas of the brain of the chick (Gallus domesticus). Baltimore: Johns Hopkins UP.

Kuhlenbeck H (1938) The ontogenetic development and phylogenetic significance of the cortex telencephali in the chick. J Comp Neurol 69:273-301.

LaVail JH, Cowan WM (1971) The development of the chick optic tectum. II. Autoradiographic studies. Brain Res 28:421-441.

Medina L, Reiner A (2000) Do birds possess homologues of mammalian primary visual, somatosensory and motor cortices? Trends Neurosci 23:1-12.

Miller MW, Nowakowski RS (1988) Use of bromodeoxyuridine-immunohistochemistry to examine the proliferation, migration and time of origin of cells in the central nervous system. Brain Res 457:44-52.

Mullen RJ, Buck CR, Smith AM (1992) NeuN, a specific nuclear neuronal protein in vertebrates. Development 116:201-211.

Mulrenin EM, Witkin JW, Silverman A-J (1999) Embryonic development of the gonadotropin-releasing hormone $(\mathrm{GnRH})$ system in the chick: a spatio-temporal analysis of GnRH neuronal generation, site of origin, and migration. Endocrinology 140:422-433.

Northcutt RG, Kaas JH (1995) The emergence and evolution of mammalian neocortex. Trends Neurosci 18:373-379.

Primmett DRN, Norris WE, Carlson GJ, Keynes RJ, Stern CD (1989) Periodic segmental anomalies induced by heat shock in the chick embryo are associated with the cell cycle. Development 105:119-130.

Puelles L, Kuwana E, Puelles E, Rubenstein JLR (1999) Comparison of 
the mammalian and avian telencephalon from the perspective of gene expression data. Eur J Morphol 37:139-150.

Puelles L, Kuwana E, Puelles E, Bulfone A, Shimamura K, Keleher J, Smiga S, Rubenstein JLR (2000) Pallial and subpallial derivatives in the embryonic chick and mouse telencephalon, traced by the expression of the genes Dlx-2, Emx-1, Nkx-2.1, Pax-6, and Tbr-1. J Comp Neurol 424:409-438.

Rakic P (1974) Neurons in the monkey visual cortex: systematic relation between time of origin and eventual disposition. Science 183:425-427.

Reiner A, Karten HJ (1983) The laminar source of efferent projections from the avian Wulst. Brain Res 275:349-354.

Reiner A, Brauth SE, Karten HJ (1984) Evolution of the amniote basal ganglia. Trends Neurosci 7:320-325.

Repka AM, Adler R (1992) Accurate determination of the time of cell birth using a sequential labeling technique with [3H]-thymidine and bromodeoxyuridine ("window labeling"). J Histochem Cytochem 40:947-953.

Shimada M, Langman J (1970) Cell proliferation, migration and differentiation in the cerebral cortex of the golden hamster. J Comp Neurol 139:227-244.

Sidman RL, Rakic P (1982) Development of the human central nervous system. In: Histology and histopathology of the human nervous system, Vol 1 (Haymaker W, Adams RD, eds), pp 3-145. Springfield, IL: Thomas.

Sidman RL, Miale IL, Feder N (1959) Cell proliferation and migration in the primitive ependymal zone: an autoradiographic study of histogenesis in the nervous system. Exp Neurol 1:322-333.

Smart IHM (1985) Differential growth of the cell production systems in the lateral wall of the developing mouse telencephalon. J Anat 141:219-229.

Smart IHM, Sturrock RR (1979) Ontogeny of the neostriatum. In: The neostriatum (Divac I, Oberg R, eds), pp 127-146. Oxford: Pergamon.

Smith Fernandez A, Pieau C, Repérant J, Boncinelli E, Wassef M (1998) Expression of the Emx-1 and Dlx-1 homeobox genes define three mo- lecularly distinct domains in the telencephalon of mouse, chick, turtle and frog embryos: implications for the evolution of telencephalic subdivisions in amniotes. Development 125:2099-2111.

Striedter GF (1997) The telencephalon of tetrapods in evolution. Brain Behav Evol 49:179-213.

Striedter GF (1999) Homology in the nervous system: of characters, embryology and levels of analysis. In: Novartis foundation symposium, Vol 222 (Bock GR, Cardew G, eds), pp 158-172. Chichester, UK: Wiley.

Striedter GF, Beydler S (1997) Distribution of radial glia in the developing telencephalon of chicks. J Comp Neurol 387:399-420.

Striedter GF, Marchant TA, Beydler S (1998) The "neostriatum" develops as part of the lateral pallium in birds. J Neurosci 18:5839-5849.

Takahashi T, Nowakowski RS, Caviness Jr VS (1992) BUdR as an S-phase marker for quantitative studies of cytokinetic behaviour in the murine cerebral ventricular zone. J Neurocytol 21:185-197.

Tsai HM, Garber BB, Larramendi LMH (1981a) Thymidine autoradiographic analysis of telencephalic histogenesis in the chick embryo. I. Neuronal birthdates of telencephalic compartments in situ. J Comp Neurol 198:275-292.

Tsai HM, Garber BB, Larramendi LMH (1981b) Thymidine autoradiographic analysis of telencephalic histogenesis in the chick embryo. II. Dynamics of neuronal migration, displacement and aggregation. J Comp Neurol 198:293-306.

van der Kooy D, Fishell G (1987) Neuronal birthdate underlies the development of striatal compartments. Brain Res 401:155-161.

van Tienhoven A, Juhász LP (1962) The chicken telencephalon, diencephalon and mesencephalon in stereotaxic coordinates. J Comp Neurol 118:185-197.

Youngren OM, Phillips RE (1978) A stereotaxic atlas of the brain of the three-day-old domestic chick. J Comp Neurol 181:567-600.

Yurkewicz L, Lauder JM, Marchi M, Giacobini E (1981) ${ }^{3} \mathrm{H}$-Thymidine long survival autoradiography as a method for dating the time of neuronal origin in the chick embryo: the locus coeruleus and cerebellar Purkinje cells. J Comp Neurol 203:257-267. 